\title{
Laboratory Evaluation of Cuff Pressure Control Methods
}

\author{
Sherry A Babic and Robert L Chatburn
}

\begin{abstract}
BACKGROUND: Automatic cuff pressure $\left(P_{\text {cuff }}\right)$ control devices for artificial airways are available, yet there are no standards or data to support their use. We hypothesized that airway pressure oscillations during mechanical ventilation are transmitted to $P_{\text {cuff }}$; and that the change in mean $P_{\text {cuff }}$ $\left(\Delta \mathbf{P}_{\text {cuff }}\right)$ is zero during mechanical ventilation with controlled or uncontrolled $\mathbf{P}_{\text {cuff }}$. METHODS: Experiments lasted $12 \mathrm{~h}$, and 2 inspiratory pressure targets $\left(P_{\text {insp }}\right)$ were established. We tested 3 automatic devices (Intellicuff Standalone, PressureEyes, and Tracoe) and one manual method for uncontrolled $P_{\text {cuff }}$. We utilized a training mannequin with an 8-mm endotracheal tube to assess pressure-controlled continuous mechanical ventilation with the following parameters: breathing frequency $=20$ breaths $/ \mathrm{min}, T_{I}=1.0 \mathrm{~s}$, PEEP $=10 \mathrm{~cm} \mathrm{H}_{2} \mathrm{O}$, and $P_{\text {insp }}=10$ and $40 \mathrm{~cm}_{2} \mathrm{O}$. For automatic cuff pressure control, we used a data acquisition system. For manual cuff pressure control, $P_{\text {cuff }}$ was set once and measured after mechanical ventilation. Initial $P_{\text {cuff }}$ was $25 \mathrm{~cm} \mathbf{H}_{2} \mathrm{O}$, and $\Delta \mathbf{P}_{\text {cuff }}$ was calculated as final mean $\mathbf{P}_{\text {cuff }}-$ initial mean $\mathbf{P}_{\text {cuff }}$. Data for $\Delta \mathbf{P}_{\text {cuff }}$ were compared with $t$ tests and reported as mean (SD). RESULTS: Airway pressure oscillations during ventilation

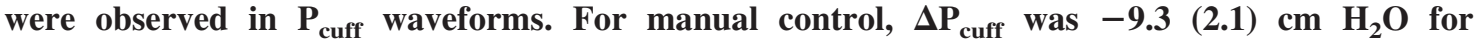
$P_{\text {insp }}=10 \mathrm{~cm} \mathrm{H} \mathrm{H}_{2} \mathrm{O}$ and $-8.1(1.1) \mathrm{cm} \mathrm{H}_{2} \mathrm{O}$ for $\mathrm{P}_{\text {insp }}=40 \mathrm{~cm} \mathrm{H}_{2} \mathrm{O}$ (vs $\left.0, P<.001\right)$. There was no difference in $\Delta P_{\text {cuff }}$ for $P_{\text {insp }}=10 \mathrm{~cm} \mathrm{H}_{2} \mathrm{O}$ versus $40 \mathrm{~cm} \mathrm{H}_{2} \mathrm{O}(P=.21)$. $\Delta P_{\text {cuff }}$ was only $\pm 0.3 \mathrm{~cm} \mathrm{H}_{2} \mathrm{O}$ for automatic control, which we deemed clinically unimportant. CONCLUSIONS: Automatic devices do not regulate ventilatory pressure oscillations, but they do control mean $\mathbf{P}_{\text {cuff }}$ and keep $\Delta \mathbf{P}_{\text {cuff }}$ well below a clinically important threshold. The large $\Delta \mathbf{P}_{\text {cuff }}$ seen with uncontrolled $\mathbf{P}_{\text {cuff }}$ warrants periodic monitoring. Further studies are needed to determine the source of $\Delta \mathbf{P}_{\text {cuff }}$ and the physiologic effects of $\mathbf{P}_{\text {cuff }}$ oscillations during mechanical ventilation. Key words: airway management; mechanical ventilation; endotracheal tube; cuff pressure regulators. [Respir Care 2020;65(1):62-67. (C) 2020 Daedalus Enterprises]
\end{abstract}

\section{Introduction}

Regulation of endotracheal tube (ETT) cuff pressure is recognized as a vital component of patient care and prevention of ventilator-associated pneumonia. ${ }^{1-3}$ The goal of monitoring ETT cuff pressures is to achieve a seal be-

Ms Babic and Mr Chatburn are affiliated with the Cleveland Clinic, Respiratory Therapy Institute, Cleveland, Ohio.

Mr Chatburn discloses relationships with IngMar Medical, Drive/DeVilbiss, and imtmedical. Ms Babic has disclosed no conflicts of interest.

Correspondence: Sherry A Babic RRT, Cleveland Clinic, Respiratory Therapy Institute, M-56, 9500 Euclid Ave, Cleveland, OH 44195. Email: babics@ccf.org.

DOI: $10.4187 /$ respcare. 06728 tween the trachea and the ETT cuff with a pressure that is high enough to prevent aspiration of secretions, but low enough to avoid impeding tracheal blood flow. The American Thoracic Society recommends that cuff pressures be maintained at $>20 \mathrm{~cm} \mathrm{H}_{2} \mathrm{O}$ to prevent ventilator-associated pneumonia. ${ }^{4}$ On the other hand, studies have shown that tracheal mucosal blood flow is impeded with cuff pressures $>30 \mathrm{~cm} \mathrm{H}_{2} \mathrm{O} .{ }^{5}$ Although there are no accepted standards for the recommended range of ETT cuff pressures, we can deduce from the previous statements that cuff pressures should be kept above $20 \mathrm{~cm} \mathrm{H}_{2} \mathrm{O}$ and below $30 \mathrm{~cm} \mathrm{H}_{2} \mathrm{O}$ to avoid both under-inflation and over-inflation of the cuff.

Furthermore, there is no standard for the method or the frequency of monitoring pressure measurements. A recent study by Letvin et al $^{6}$ reported no clinical outcome benefit with frequent monitoring of cuff pressures. A study by 
Chenelle et $\mathrm{al}^{7}$ contradicted this by reporting that a continuous cuff pressure regulator was able to maintain cuff pressures within the safe range when compared to manual cuff inflation. Several cuff inflation methods have been described over the years, but there appears to be no consensus on the most reliable method for maintaining safe ETT cuff pressures. Manual methods of cuff monitoring include simple palpation of the ETT pilot balloon, manual cuff inflation using the minimal occluding volume, and the minimal leak technique. When using the minimal occluding volume method, the cuff is slowly inflated using a syringe just until no leak is heard during a positive-pressure breath. ${ }^{8}$ To perform the minimal leak technique, the cuff is slowly inflated until the air leak stops; then a small amount of air is released to allow a slight air leak at peak inspiratory pressure. ${ }^{8}$ These techniques are non-quantitative and thus yield no data with which to control cuff pressure. Hence, such methods are no longer recommended, due to the risk of mucosal damage (ie, with minimal occluding volume) or silent aspiration of pharyngeal secretions (ie, with minimal leak technique). ${ }^{9}$

Automatic cuff pressure control devices are available, but there are few data to indicate whether they are necessary. Cuff inflators (eg, Posey, Cuff Mate 2) allow the clinician to inflate and measure cuff pressure simultaneously. However, studies have indicated that the action of measuring cuff pressures with these devices contributes to a loss of cuff pressure ${ }^{10-12}$

Several factors, including ventilator pressures, patient position and/or movement, altitude, and cuff design, have been reported to alter cuff pressures. ${ }^{7,13-15}$ In addition, there may be a leak in either the cuff or the cuff inflation valve. Therefore, frequent cuff monitoring is important for patient safety. Devices that allow continuous automatic cuff pressure control would seem to provide a more stable cuff pressure during mechanical ventilation compared to the method of manual cuff inflation, which results in uncontrolled cuff pressures. The purpose of this study was to investigate this assumption. Specifically, we hypothesized that airway pressure oscillations during mechanical ventilation are transmitted to cuff pressure regardless of pressure regulation method, and that 3 different automatic cuff pressure control devices and the manual method will result in zero change in mean cuff pressure during $12 \mathrm{~h}$ of simulated mechanical ventilation.

\section{Methods}

The equipment used in this study is shown in Figure 1. We utilized the following automatic cuff pressure control devices: PressureEyes (Bay State Anesthesia, Middleton, MA); Tracoe (TRACOE Medical, Nieder-Olm, Germany); and Intellicuff standalone (Hamilton Medical, Bonaduz, Switzerland). The experimental set-up is shown in Figure

\section{QUICK LOOK}

\section{Current knowledge}

Current practice for airway management includes maintaining endotracheal tube cuff pressures between 20 and $30 \mathrm{~cm} \mathrm{H}_{2} \mathrm{O}$. Several methods and devices are used in clinical practice to monitor cuff pressures, but there are no concise guidelines regarding the method or frequency for maintaining cuff pressures. Other studies have reported that electronic cuff pressure controllers can maintain mean cuff pressure.

\section{What this paper contributes to our knowledge}

For the 3 electronic cuff pressure controllers studied, mean cuff pressure was regulated, but airway pressure oscillations during mechanical ventilation were transmitted to cuff pressures. Automatic cuff pressure controllers maintained mean cuff pressure over $12 \mathrm{~h}$. Manual cuff inflation allows a clinically important drop in mean cuff pressures over 12-14 h.

2. The outcome variable was the change in mean cuff pressure over time $\left(\Delta \mathrm{P}_{\text {cuff }}\right)$, which was the final mean cuff pressure (at $12 \mathrm{~h}$ ) minus the initial mean cuff pressure (at $3 \mathrm{~min}$ ); pressures were measured during ventilation for the continuous cuff pressure controllers and after disconnecting from ventilation for the manual method.

This study involved experimental runs that each lasted $12 \mathrm{~h}$, with 2 different inspiratory pressure targets $\left(\mathrm{P}_{\text {insp }}\right)$, defined as set inspiratory pressure above PEEP, of 10 and $40 \mathrm{~cm} \mathrm{H}_{2} \mathrm{O}$ with 3 separate ETTs, with each of the 4 different cuff pressure monitoring methods (ie, manual, Intellicuff standalone, PressureEyes, and Tracoe) for a total of 24 experimental runs. An intubation mannequin (Intubation Airway, Laerdal, Stavanger, Norway) was intubated with an 8-mm inner diameter ETT and connected to a mechanical ventilator with the following settings: pressure-controlled continuous mechanical ventilation mode (named A/C Pressure Control on the Medtronics PB 840 ventilator), breathing frequency $=20$ breaths $/ \mathrm{min}$, inspiratory time $=1.0 \mathrm{~s}$, PEEP $=10 \mathrm{~cm} \mathrm{H}_{2} \mathrm{O}$, and $\mathrm{P}_{\text {insp }}=$ $10 \mathrm{~cm} \mathrm{H}_{2} \mathrm{O}$ above PEEP and $40 \mathrm{~cm} \mathrm{H}_{2} \mathrm{O} .{ }^{16}$ When testing the continuous cuff pressure control devices, the ETT pilot balloon was connected to the first port of a 3-way stopcock. The second port was connected to a pressure transducer (Pneumotach Amplifier 1, series 1110, Hans Rudolph, Shawnee Mission, Kansas) with a digital-to-analog converter (PowerLab 8/30, ADInstruments Bella Vista, New South Wales, Australia) and data acquisition software (JT Posey company acquired by TIDI products, Lake Forest, IL) to continuously record cuff pressure values. The third port was used to connect an automatic pressure 


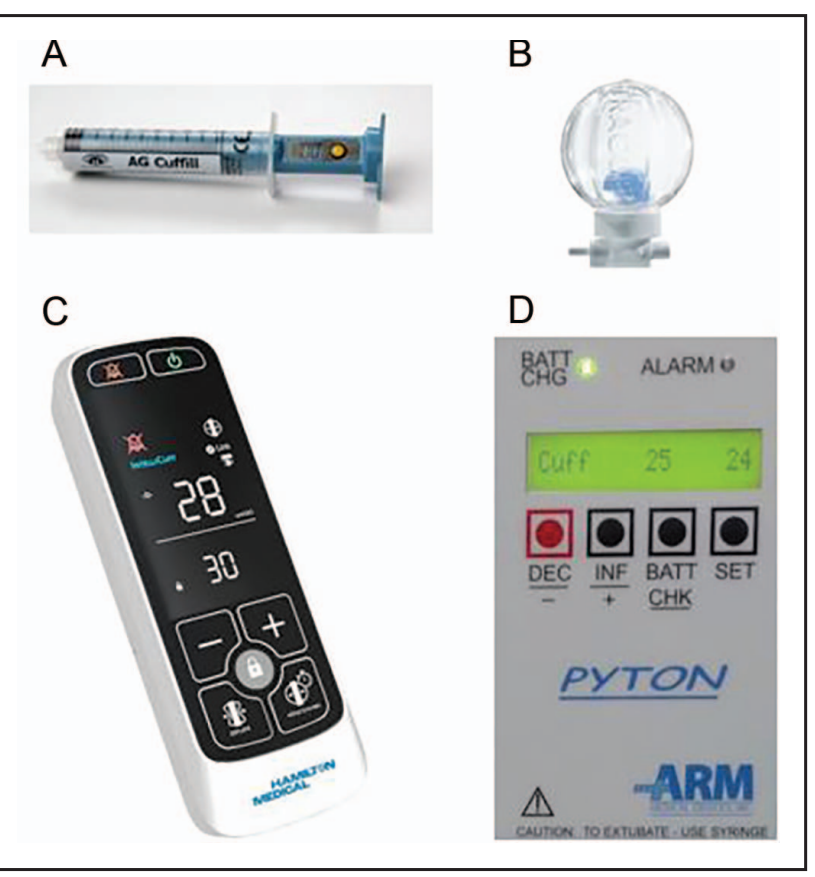

Fig. 1. Equipment used in the study. A: Cuff Inflator-AG Cuffill, B: Tracoe Smart Cuff Manager, C: Intellicuff Standalone (automatic cuff pressure control device), and D: PressureEyes (automatic cuff pressure control device).

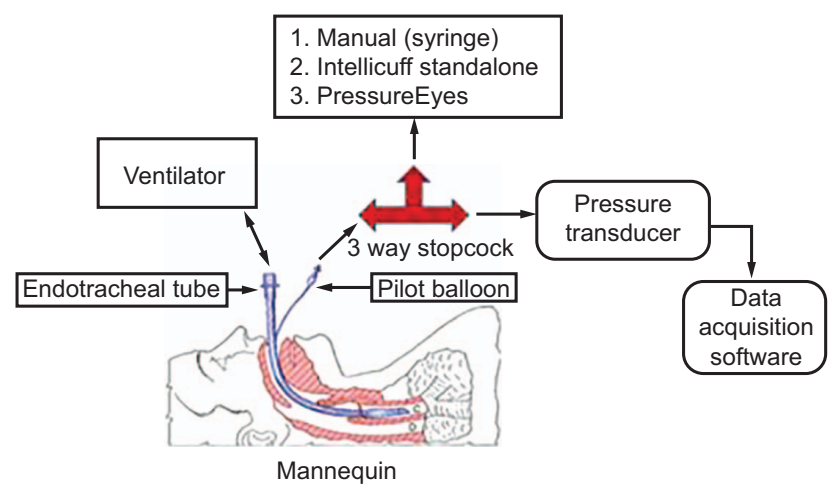

Fig. 2. Experimental set-up (continuous cuff pressure controlling devices).

controller (Fig. 2). To test the manual method, the ETT was first inflated with a Posey Cufflator (Posey, Arcadia, California). After disconnecting the Posey Cufflator, the pilot balloon was directly attached to the pressure transducer. This procedure was repeated until the initial cuff pressure on the pressure transducer read $25 \mathrm{~cm} \mathrm{H}_{2} \mathrm{O}$.

With each experimental run, the ETT cuff was inflated either manually or using an automatic pressure controller to an initial cuff pressure of $25 \mathrm{~cm} \mathrm{H}_{2} \mathrm{O}$. Pressure data were recorded at $3 \mathrm{~min}$ after ventilation began (to allow for stabilization of cuff pressures; designated time $=0$ ) and then at 2, 4, 6, 8, 10, and $12 \mathrm{~h}$ of ventilation. The DataPad feature of LabChart 8 was used to calculate av- erage values ( 5 min sections of data) for mean cuff pressure at each time point.

After inspecting the data for the manual method, it was apparent that the $\Delta \mathrm{P}_{\text {cuff }}$ could be clinically important. In an attempt to remove possible leaks due to the measurement equipment, we repeated the experiment with several modifications. First, we eliminated the continuous pressure monitoring line and made measurements only at the start and end of the 14-h period. Next, we used the AG Cuffill device (Mercury Medical, Clearwater, Florida) for inflating and measuring cuff pressures to estimate the pressure drop due to measurement itself. The pressure drop due to measurement was estimated as follows:

1. The Cuffill device was turned on.

2. After a pressure reading of zero, the device plunger was set to $1 \mathrm{~mL}$ and attached to the pilot balloon.

3. The plunger was used to inflate ETT cuff to $25 \mathrm{~cm} \mathrm{H}_{2} \mathrm{O}$.

4. The AG Cuffill was disconnected from the pilot balloon.

5. The plunger was set to $0 \mathrm{~mL}$, turned back on, and then reattached to the pilot balloon.

6. The new pressure was recorded, and the difference in the 2 pressures was defined as the pressure change due to measurement.

This procedure was repeated 30 times, and an average pressure change due to measurement was calculated as a correction factor for estimating $\Delta \mathrm{P}_{\text {cuff }}$ (ie, the correction factor was added to the observed cuff pressure change at $14 \mathrm{~h}$ to estimate $\Delta \mathrm{P}_{\text {cuff }}$ ). Finally, measurements at $0 \mathrm{~h}$ were made prior to connecting the ventilator, and measurements at $14 \mathrm{~h}$ were made after disconnecting the ventilator to ensure steady state.

The significance of $\Delta \mathrm{P}_{\text {cuff }}$ for the manual method was evaluated using a 1-sample $t$ test with significance indicated by $P<.05$ (testing the hypothesis that $\Delta \mathrm{P}_{\text {cuff }}=0$ ) and a 2-sample $t$ test to compare $\Delta \mathrm{P}_{\text {cuff }}$ for $\mathrm{P}_{\text {insp }}=10 \mathrm{~cm} \mathrm{H}_{2} \mathrm{O}$ versus $\mathrm{P}_{\text {insp }}=40 \mathrm{~cm} \mathrm{H}_{2} \mathrm{O}$.

The $\Delta \mathrm{P}_{\text {cuff }}$ for the automatic devices was always within $\pm 0.3 \mathrm{~cm} \mathrm{H}_{2} \mathrm{O}$, which was considered to be within the error tolerance of the measurement devices and thus statistical analysis was deemed unnecessary.

\section{Results}

Figure 3 shows representative cuff pressure waveforms for the different $P_{\text {insp }}$ settings. $P_{\text {insp }}$ values were reflected in changing cuff pressure. As set $\mathrm{P}_{\text {insp }}$ increased, the amplitude of the transmitted pressure increased as expected.

For the manual method, Figures 4 and 5 show that mean (SD) $\Delta \mathrm{P}_{\text {cuff }}$ values were $-9.3(2.1) \mathrm{cm} \mathrm{H}_{2} \mathrm{O}$ for $\mathrm{P}_{\text {insp }}=10$ $\mathrm{cm}_{2} \mathrm{O}$ and $-8.1(1.1) \mathrm{cm} \mathrm{H}_{2} \mathrm{O}$ for $\mathrm{P}_{\text {insp }}=40 \mathrm{~cm} \mathrm{H}_{2} \mathrm{O}$. Both of these values were significantly different from the 
A Inspiratory Pressure Target $=10 \mathrm{~cm} \mathrm{H}_{2} \mathrm{O}$
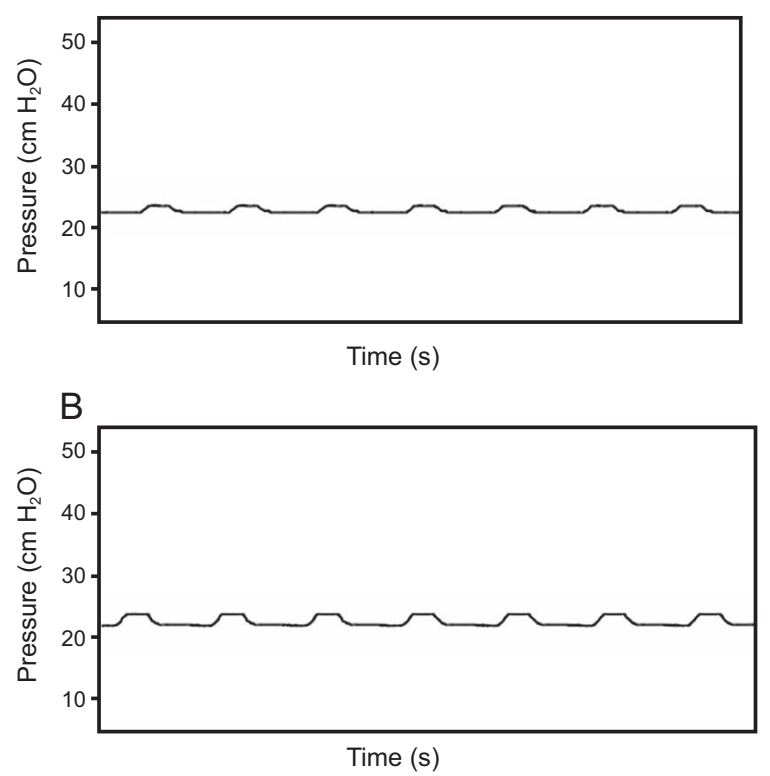

C
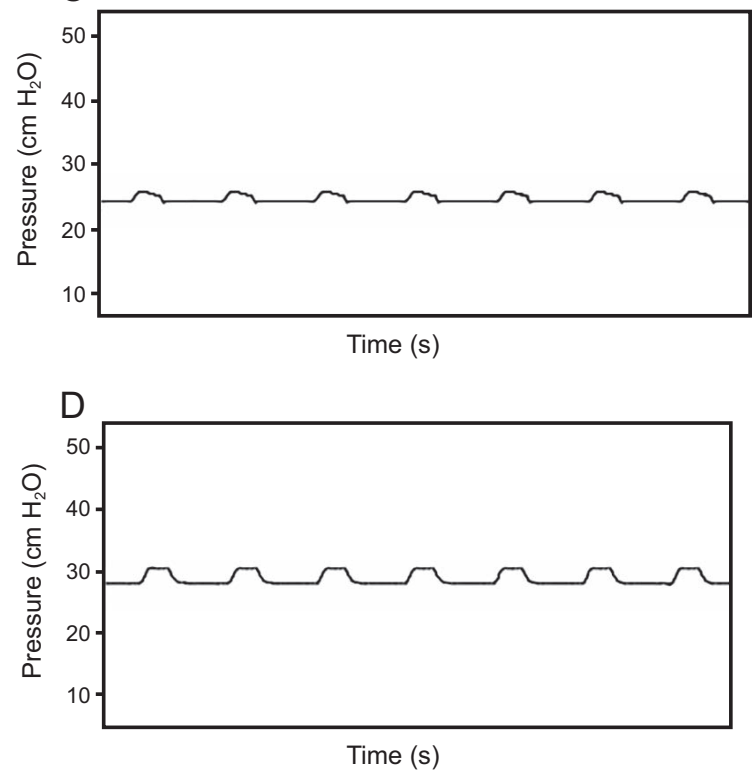

Inspiratory Pressure Target $=40 \mathrm{~cm} \mathrm{H}_{2} \mathrm{O}$
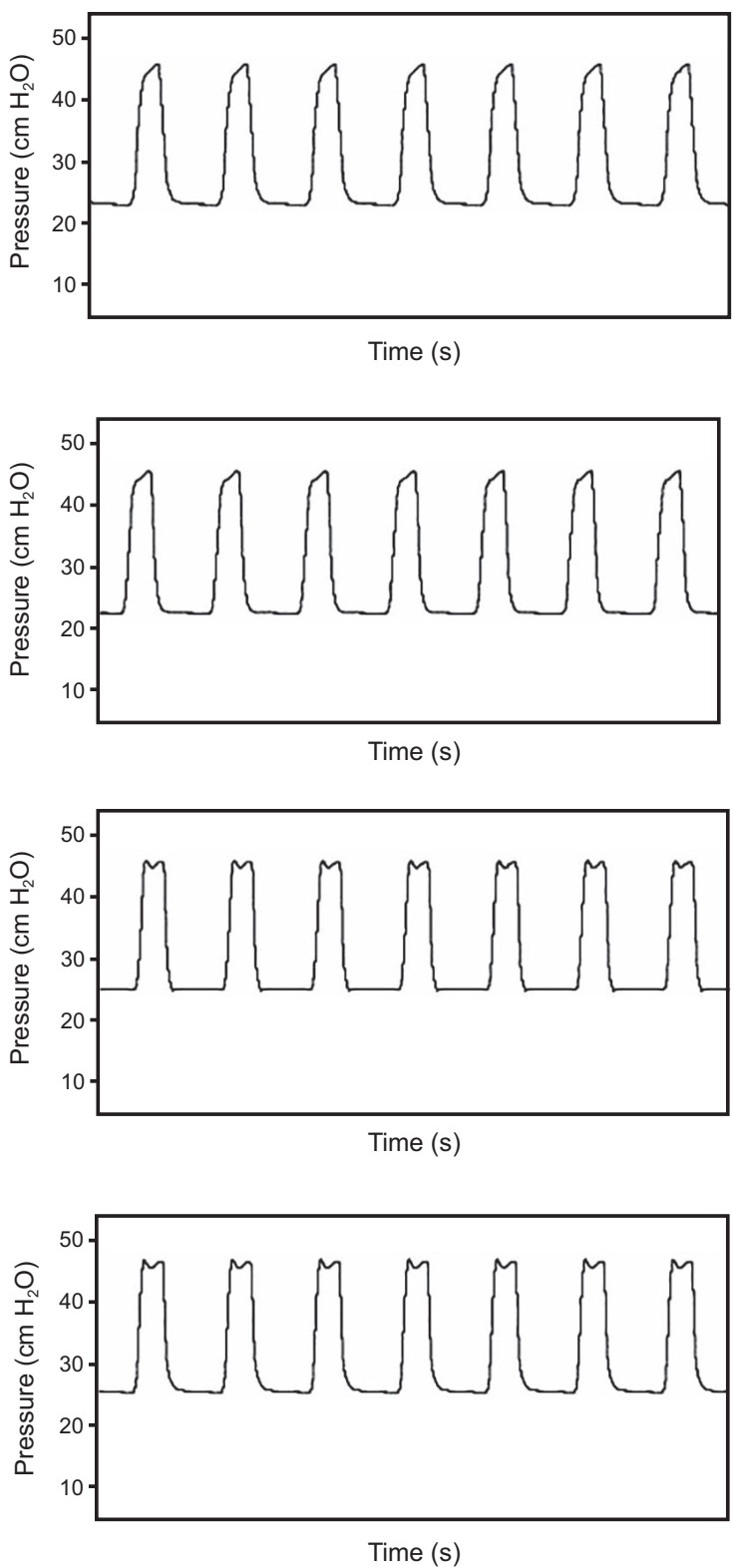

Fig. 3. Representative cuff pressure waveforms for different inspiratory pressure settings. A: IntelliCuff. B: PressureEyes. C: Tracoe. D: Manual.

expected drop of $0 \mathrm{~cm} \mathrm{H}_{2} \mathrm{O}(P<.001)$. However, there was no difference in $\Delta \mathrm{P}_{\text {cuff }}$ for $\mathrm{P}_{\text {insp }}=10 \mathrm{~cm} \mathrm{H}_{2} \mathrm{O}$ versus $\mathrm{P}_{\text {insp }}=$ $40 \mathrm{~cm} \mathrm{H}_{2} \mathrm{O}(P=.21)$.

The difference in $\Delta \mathrm{P}_{\text {cuff }}$ between the $2 \mathrm{P}_{\text {insp }}$ values was not statistically significant, although the $\Delta \mathrm{P}_{\text {cuff }}$ for $\mathrm{P}_{\text {insp }}=40 \mathrm{~cm} \mathrm{H}_{2} \mathrm{O}$ was slightly lower. However, upon repeating the experiment without continuous measurement of pressure, both ventilating pressures resulted in essentially the same $\Delta \mathrm{P}_{\text {cuff }}$. For $\mathrm{P}_{\text {insp }}=10 \mathrm{~cm} \mathrm{H}_{2} \mathrm{O}, \Delta \mathrm{P}_{\text {cuff }}$ was $-11.1(2.0) \mathrm{cm} \mathrm{H}_{2} \mathrm{O}$, and for $\mathrm{P}_{\text {insp }}=40 \mathrm{~cm} \mathrm{H}_{2} \mathrm{O}$, $\Delta \mathrm{P}_{\text {cuff }}$ was $-10.6(1.3) \mathrm{cm} \mathrm{H}_{2} \mathrm{O}(P=.69)$.
The average $\Delta \mathrm{P}_{\text {cuff }}$ for the automatic devices (Figs. 4 and 5) were virtually the same and not clinically important at both low and high ventilating pressures. The most extreme $\Delta \mathrm{P}_{\text {cuff }}$ values were $-0.3(0.4)$ with the Intellicuff, $0.3(0.1)$ with the PressureEyes, and $-0.3(0.3)$ with the Tracoe.

\section{Discussion}

The results of this study support the hypothesis that airway pressure oscillations are transmitted to the ETT 


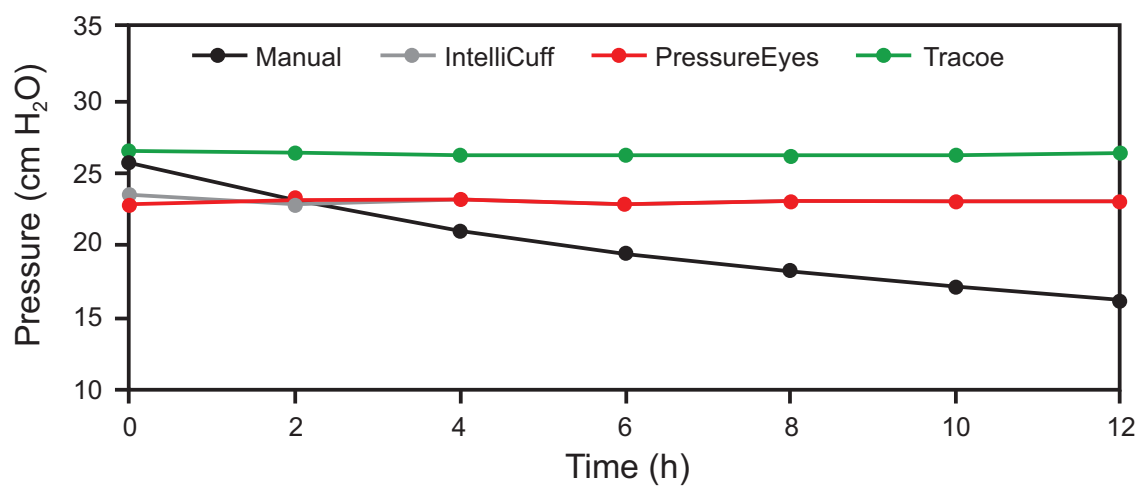

Fig. 4. Mean $\Delta \mathrm{P}_{\text {cuff }}$ at an inspiratory pressure target of $10 \mathrm{~cm} \mathrm{H}_{2} \mathrm{O}$.

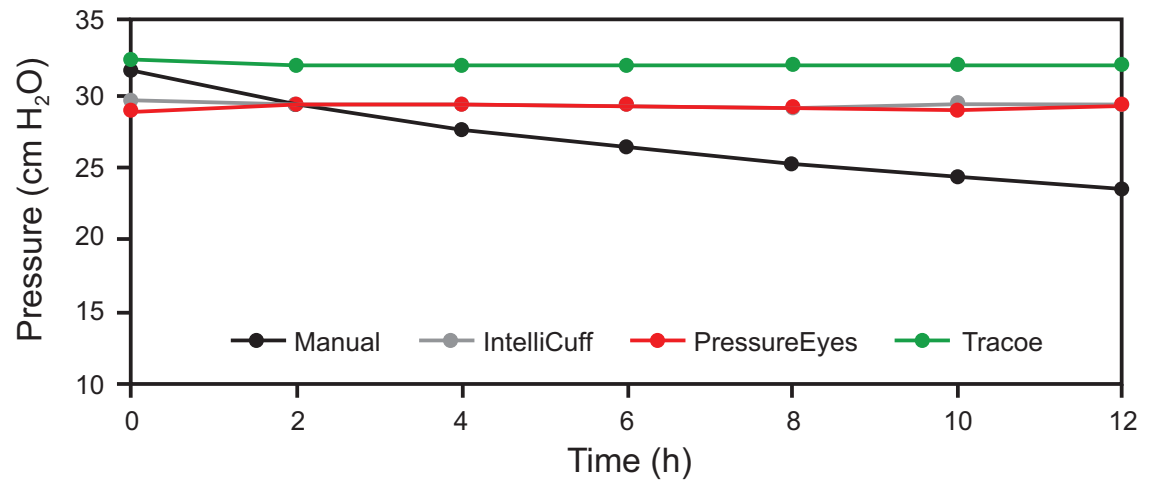

Fig. 5. Mean $\Delta \mathrm{P}_{\text {cuff }}$ at an inspiratory pressure target of $40 \mathrm{~cm} \mathrm{H}_{2} \mathrm{O}$.

cuff and that the automatic cuff pressure controllers we examined do not dampen these pressure fluctuations. Further studies are needed to determine whether the cyclic variations in cuff pressure pose a risk to patients.

The electronic pressure controllers regulated mean cuff pressures and kept the changes in cuff pressure well below a clinically important threshold (ie, $\Delta \mathrm{P}_{\text {cuff }}<1 \mathrm{~cm} \mathrm{H}_{2} \mathrm{O}$ ). On the other hand, uncontrolled cuff pressure (ie, the manual method) resulted in a $\Delta \mathrm{P}_{\text {cuff }}$ over $12 \mathrm{~h}$ of -8 to $-9 \mathrm{~cm} \mathrm{H}_{2} \mathrm{O}$. This drop may be large enough to warrant monitoring of manually filled ETT cuffs at intervals of at least $12 \mathrm{~h}$, given that an initial pressure in the middle of the acceptable range (eg, $25 \mathrm{~cm} \mathrm{H}_{2} \mathrm{O}$ ) could drop below the acceptable threshold of $20 \mathrm{~cm} \mathrm{H}_{2} \mathrm{O}$ after $12 \mathrm{~h}$. We do not know why cuff pressure drops with the manual method, and further study is required to understand this observation.

Our results are comparable to a study done by Chenelle et $\mathrm{al}^{7}{ }^{7}$ who reported the presence of cyclic variations in cuff pressure and that the $\Delta \mathrm{P}_{\text {cuff }}$ during ventilation was clinically important for the manual technique. The study done by Dave et al ${ }^{17}$ also indicated that cuff pressure fluctuates between inspiration and expiration.

Several limitations of this study must be mentioned. First, there were no positional changes in the mannequin, which has been reported to have an effect on cuff pressures. ${ }^{7}$ Only one type (ie, material and shape) of ETT was used for this study; other ETTs may perform differently. ${ }^{15}$ Finally, the airway of the mannequin was not dynamic, nor was it heated to body temperature or humidified, which may have had an effect on cuff pressures. ${ }^{18}$

\section{Conclusions}

Many factors have been reported to affect cuff pressures, including cuff material/shape, ${ }^{1,2}$ patient positioning, 7,14 ventilatory pressures, ${ }^{7,18}$ altitude, ${ }^{16}$ coughing, and suctioning. ${ }^{8}$ Hence, artificial airways necessitate vigilant monitoring to maintain cuff pressures within the recommended range of $20-30 \mathrm{~cm} \mathrm{H}_{2} \mathrm{O}$. Uncontrolled cuff pressure (ie, simple manual inflation and checking) results in a clinically important drop in pressure over time. Electronic pressure controllers can regulate mean cuff pressures and keep the $\Delta \mathrm{P}_{\text {cuff }}$ well below a clinically important threshold. More studies are needed to establish guidelines regarding the method and frequency of monitoring cuff pressures for artificial airways, and to determine the risk that cyclic cuff pressures pose to tracheal wall mucosa. 


\section{Methods of Cuff Pressure Control}

\section{REFERENCES}

1. Rouzé A, Jaillette E, Poissy J, Préau S, Nseir S. Tracheal tube design and ventilator-associated pneumonia. Respir Care 2017;62(10):13161323.

2. Rello J, Soñora R, Jubert P, Artigas A, Rué M, Vallés J. Pneumonia in intubated patients: role of respiratory airway care. Am J Respir Crit Care Med 1996;154:111-115.

3. Nseir S, Brisson H, Marquette C, Chaud P, Di Pompeo C, Diarra M, Durocher A. Variations in endotracheal cuff pressure in intubated critically ill patients: prevalence and risk factors. Eur J Anaesthesiol 2009;26(3):229-234.

4. American Thoracic Society Documents. Guidelines for the management of adults with hospital-acquired, ventilator-associated, and healthcare-associated pneumonia. Am J Respir Crit Care Med 2005; 171:388-416.

5. Seegobin RD, van Hasselt GL. Endotracheal cuff pressure and tracheal mucosal blood flow: endoscopic study of effects of four large volume cuffs. BMJ 1984;288(31):965-968.

6. Letvin, A, Kremer P, Silver PC, Samih N, Reed-Watts P, Kollef MH. Frequent vs infrequent monitoring of endotracheal tube cuff pressures. Respir Care 2018;63(5):495-501.

7. Chenelle CT, Oto J, Sulemanji D, Fisher DF, Kacmarek RM. Evaluation of an automated endotracheal tube cuff controller during simulated mechanical ventilation. Respir Care 2015;60(2):183-190.

8. Sole ML, Penoyer DA, Su X, Jimenez E, Kalita SJ, Poalillo E, et al. Assessment of endotracheal cuff pressure by continuous monitoring: a pilot study. Am J Crit Care 2009;18(2):133-143.

9. Hess DR. Tracheostomy tubes and related appliances. Respir Care 2005;50(4):497-510.
10. Asai S, Motoyama A, Matsumoto Y, Konami H, Imanaka H, Nishimura M. Decrease in cuff pressure during the measurement procedure: an experimental study. J Intensive Care 2014;2(34):1-5.

11. Blanch P. Laboratory evaluation of 4 brands of endotracheal tube cuff inflator. Respir Care 2004;49(2):166-173.

12. Aeppli, N, Lindauer, B, Steurer, M.P, Weiss, M, Dullenkopf, A. Endotracheal tube cuff pressure changes during manual cuff pressure control manoeuvres: an in-vitro assessment. Acta Anaesthesiol Scand. 2019;(63):55-60.

13. Lizy C, Swinnen W, Labeau S, Poelaert J, Vogelaers D, Vandewoude $\mathrm{K}$, et al. Cuff pressure of endotracheal tubes after changes in body position in critically ill patients treated with mechanical ventilation. Am J Crit Care 2014;23(1):e1-e8.

14. Mafjdpour C, Mauch J, Dave MH, Spielmann N, Weiss M. Comparison of air-sealing characteristics of tapered-vs. cylindrical-shaped high-volume, low-pressure tube cuffs. Acta Anaesthesiol Scand 2012; 56:230-235

15. Blakeman T, Rodriquez D Jr, Woods J, Cox D, Elterman J, Branson R. Automated control of endotracheal tube cuff pressure during simulated flight. J Trauma Acute Care Surg 2016;81(5 Suppl 2):S116S120.

16. Chatburn RL, El-Khatib M, Mireles-Cabodevila E. A taxonomy for mechanical ventilation: 10 fundamental maxims. Respir Care 2014; 59(11):1747-1763.

17. Dave MH, Spielmann N, Mauch J, Weiss M. Effect of Lanz pressure regulating valve on self-sealing mechanism and air leakage across the tracheal tube cuffs in a benchtop model. J Intensive Care Med 2012;28(4):247-251.

18. Atlas GM. A mathematical model of differential tracheal tube cuff pressure: effects of diffusion and temperature. J Clin Monit Comput 2005;19:415-425. 